CONF. $791205-16$

CREEP RELAXATION OF FUEL PIN BENDING AND OVALLING STRESSES

D.P. Chan

R.J. Jackson

June 1979

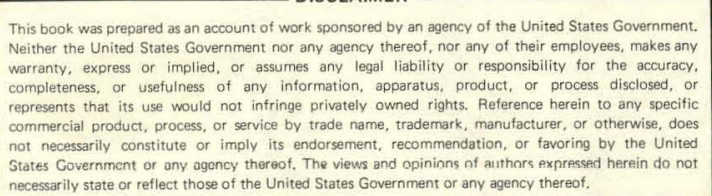

ecessarily state or reflect those of the United States Government or any agency thereof.

ASME Winter Annual Meeting

Dec. 2-7, 1979, New York, N.Y.

HANFORD ENGINEERING DEVELOPMENT LABORATORY

Operated by Westinghouse Hanford Company, a subsidiary of

Westinghouse Electric Corporation, under the Department of

Energy Contract Mo. EY-76-C-14-2170 


\section{DISCLAIMER}

This report was prepared as an account of work sponsored by an agency of the United States Government. Neither the United States Government nor any agency Thereof, nor any of their employees, makes any warranty, express or implied, or assumes any legal liability or responsibility for the accuracy, completeness, or usefulness of any information, apparatus, product, or process disclosed, or represents that its use would not infringe privately owned rights. Reference herein to any specific commercial product, process, or service by trade name, trademark, manufacturer, or otherwise does not necessarily constitute or imply its endorsement, recommendation, or favoring by the United States Government or any agency thereof. The views and opinions of authors expressed herein do not necessarily state or reflect those of the United States Government or any agency thereof. 


\section{DISCLAIMER}

Portions of this document may be illegible in electronic image products. Images are produced from the best available original document. 


\title{
CREEP RELAXATION OF FUEL PIN \\ BENDING AND OVALLING STRESSES
}

D. P. Chan

Senior Engineer

Member ASME

\author{
R. J. Jackson \\ Manager \\ Assembly Design and Performance
}

Westinghouse Hanford Company

Richland, WA 99.35?

(To be submitted to the ASME Winter Annual Meeting, December. 2-7, 1979, New York City) 


\section{NOMENCLATURE}

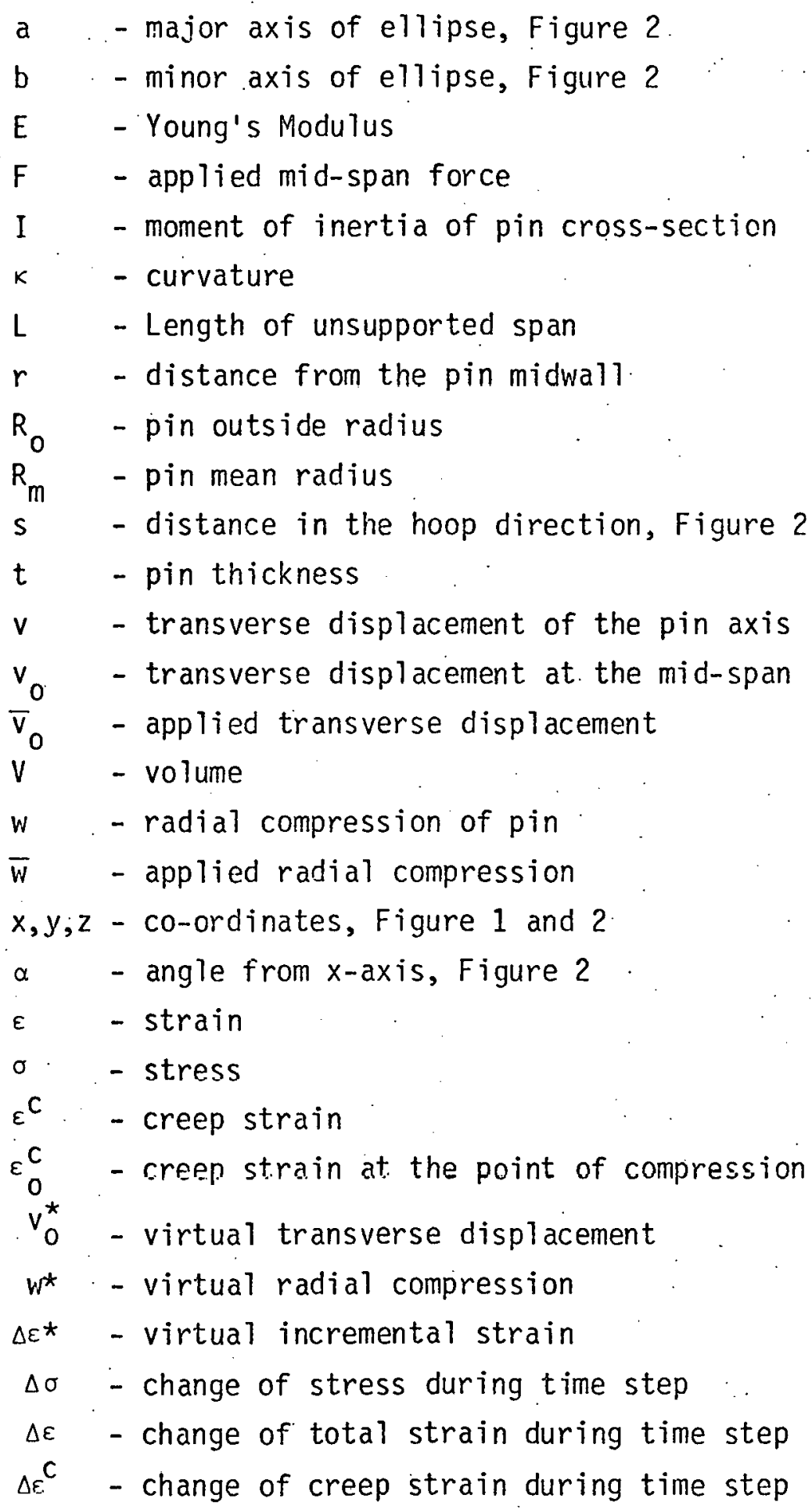




\section{ABSTRACT}

Analytical methods for calculating fuel pin cladding bending and ovalling stresses due to pin bundleduct mechanical interaction taking into account. nonlinear creep are presented. Calculated results are in close agreement.with finite element results by MARC-CDC program. The methods are used to investigate the effect of creep on the ETR fuel cladding bending and ovalling stresses. It is concluded that the cladding of 316 SS $20 \% \mathrm{CW}$ and reference design has high creep rates in the FTR core region to keep the bending and ovalling stresses to low levels. 


\section{INTRODUCTION}

For a driver fuel assembly in the Fast Test Reactor, the fuel pins are separated from each other inside hexagonal ducts by means of wire-wraps. At the beginning-of-life, there is a design clearance of $0.51 \mathrm{~mm}(0.02 \mathrm{in.})$ across flats between a theroretically tight fuel pin bundle and its duct. During irradiation, differential growth between the pin bundle and its duct occurs mainly because of irradiation swelling. Since swelling is dependent on temperature, the hot fuel pin bundle will swell faster than the relatively less hot duct. How the bundle-duct clearance decreases with irradiation history can be estimated by computer codes like POROSITY. (1) For a driver assembly in the FTR row 1 position, theoretical contact between the pin bundle and its duct occurs in approximately $11 / 2$ reactor cycles (3600 hrs.). At the end of 3 reactor cycles, the maximum interference between the pin bundle and its duct is approximately $1.78 \mathrm{~mm}(0.07 \mathrm{in}$.$) . One of the consequences of the$ bundle-duct interference is the bending and ovaliing of fuel pins. In general the edge pins will experience the worst bending, and the pin behind the edge pin, the worst ovalling. In Reference 2, a spring model of the fuel pin bundle is presented, which has been correlated against bundle compression test data. The spring model can be used to separate bending and ovalling components from the bundle-duct interference for any time increment. Since the bundle-duct interference increases with time, the cladding bending and ovalling stresses without creep relaxation will in turn increase with time. However, in the fuel region of the pin; fast neutron flux induces creep which relaxes the stresses. The final stress levels in the cladding will depend on the bundle-duct interference rate and the creep relaxation rate. In the following, analytical methods for calculating bending and ovalling stresses taking into account both increasing interference and creep relaxation are presented. Bending stresses can also be created by the thermal bowing of fuel pins. For a discussion on the bending stresses due to thermal gradient, irradiation swelling, irradiation creep and support conditions, the readers are referred to Reference 3. 
It is assumed that the fuel pin designer. has (1) determined the bundleduct interference history and (2) separated the bending and ovalling components from the interference. For the determination of bending and ovaliing stresses, the following methods can be used.

\section{PIN BENDING}

Figure 1 shows the bending of a span of an edge pin by compression at the mid-span. For an edge pin wrapped with a $30 \mathrm{~cm}$ (12 in.) axial pitch wire, there are support points every $5 \mathrm{~cm}$ (2 in.) along the bundle side of the pin, and they are not in the same plane. For simplicity and a conservative estimate of the cladding bending stress, it is assumed that the compression is resisted by 2 simple supports $5 \mathrm{~cm}$ ( 2 in.) apart and in the same plane. The compression can be either force or displacement function of time. The method calls for dividing the total time into steps. The mid-span force or displacement is assumed constant within each time step and is incremented from step to step. In the following, equations for calculating cladding stress history are presented for the case of mid-span force. As will be seen later, the same equations and iterative solution procedure are applicable for mid-span displacement with minor modification.

Let the transverse displacement due to the mid-span force be:

$$
v=v_{0}\left[1-6\left(\frac{x}{L}\right)^{2}+4\left(\frac{x}{L}\right)^{3}\right]
$$

The curvature of the deformed pin is:

$$
\kappa=\frac{d^{2} v}{d x^{2}}
$$




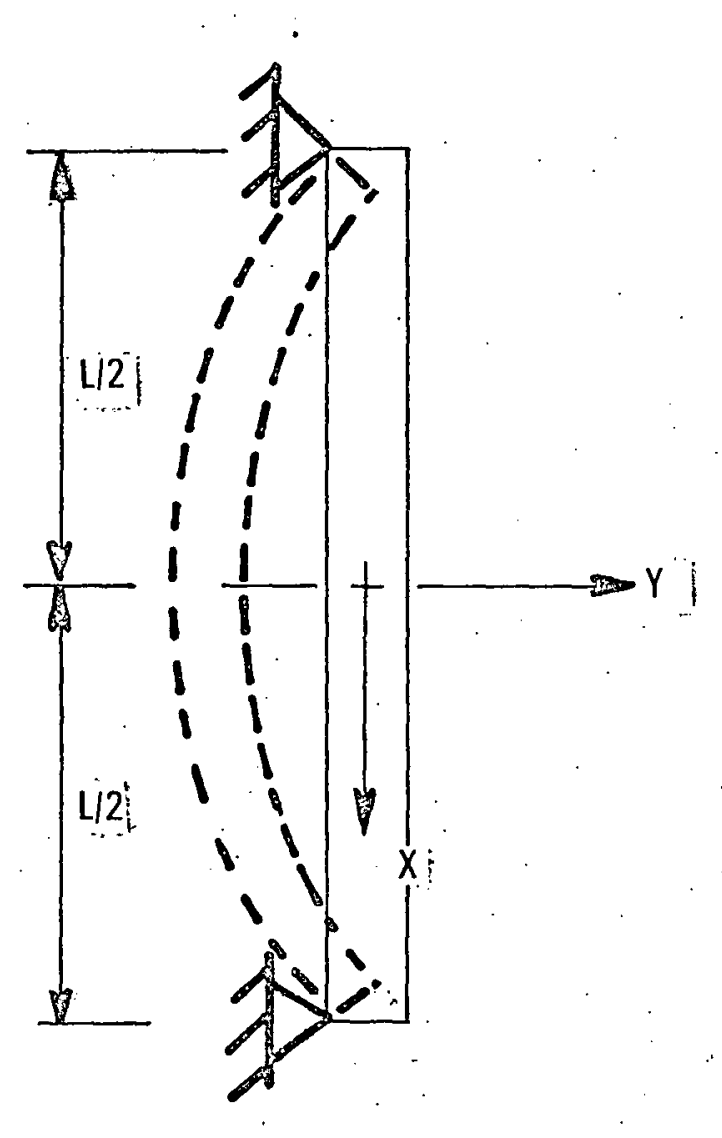

$\propto-\nabla(t) \quad$ or $F(t)$

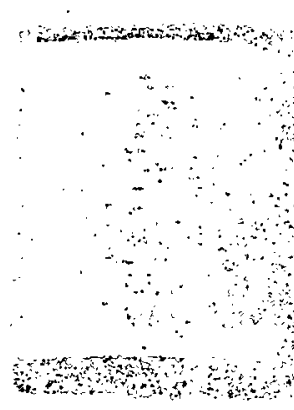

HEDL 7905-060

FIGURE 1. BENDING OF A SECTION OF AN EDGE PIN

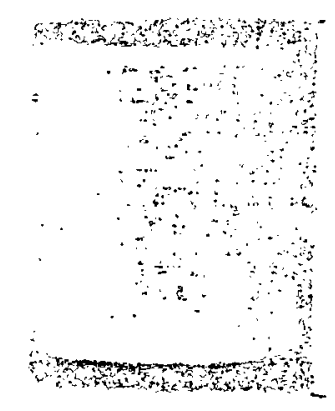


The strain of any fiber along the pin is:

$$
\begin{aligned}
\varepsilon & =y \frac{d^{2} v}{d x^{2}} \\
& =\frac{12 y v_{0}}{L^{2}}\left[1-2\left(\frac{x}{L}\right)\right]
\end{aligned}
$$

The stress and stress change of any fiber along the pin are:

$$
\begin{aligned}
\sigma & =E\left(\varepsilon-\varepsilon^{c}\right) \\
\Delta \sigma & =E\left(\Delta \varepsilon-\Delta \varepsilon^{c}\right)
\end{aligned}
$$

Since thermal strain and swelling strain do not affect bending under uniform temperature and flux, they are neglected from the stress-strain relationship.

Let the creep strain be linearly varying along the pin.

$$
\varepsilon^{c}=\varepsilon_{0}^{c}\left[1-2\left(\frac{x}{L}\right)\right]
$$

The principle of virtual work states that for a structure in equilibrium the work done by the internal forces equals the work done by the applied ludds for any small geometrically admissible displacement variation from the true one.

$$
\int_{V} \Delta \varepsilon^{*} \sigma d V=\frac{1}{2} F \Delta V_{0}^{*}
$$

where

$$
\Delta \varepsilon^{*}=\frac{12 y \Delta v_{0}^{*}}{L^{2}}\left[1-2\left(\frac{x}{L}\right)\right]
$$


and $\Delta v_{0}^{*}$ is the virtual mid-span displacement. Substituting equations (3), (4), and (6) into (5), carrying out the integrations, and setting the coefficient of $\Delta v_{0}^{*}$ to zero, the following expression for mid-span displacement at any time is obtained.

$$
v_{0}=\frac{F L^{3}}{48 E I}+\frac{L^{2}}{12 E} \int_{-R_{0}}^{R_{0}} y \varepsilon_{0}^{c} d y
$$

For any time step, the change in mid-span displacement is:

$$
\Delta v_{0}=\frac{L^{2}}{12 E} \int_{-R_{0}}^{R_{0}} y \Delta \varepsilon_{0}^{c} d y
$$

The integral in equation (8) can be expressed as:

$$
\int_{-R_{0}}^{R_{0}} \Delta \varepsilon_{0}^{c} \cdot y d y=\int_{0}^{\pi / 2} g \cdot g \cdot(\theta) d \theta
$$

where $g(\theta)=4 \Delta \varepsilon_{0}^{c} R_{m}^{2}, t \cos \theta$.

Numerical integration of the right-hand-ride of equation (9) can be performed using Newton-Cotes quadrature formula:

$$
\int_{0}^{\pi / 2} g(\theta) d \theta=\frac{5 \Delta}{288}\left[19 g\left(\theta_{0}\right)+75 g\left(\theta_{1}\right)\right.
$$




$$
\begin{aligned}
& +50 \mathrm{~g}\left(\Theta_{, 2}\right)+50 \mathrm{~g}\left(\theta_{3}\right)+75 \mathrm{~g}\left(\theta_{4}\right)+38 \mathrm{~g}\left(\theta_{5}\right) \\
& \left.+75 \mathrm{~g}\left(\theta_{6}\right)+50 \mathrm{~g}\left(\theta_{7}\right)+50 \mathrm{~g}\left(\theta_{8}\right)+75 \mathrm{~g}\left(\theta_{9}\right)+38 \mathrm{~g}\left(\theta_{10}\right)\right]
\end{aligned}
$$

where $\Delta=\pi / 20$

and $g\left(\theta^{i}\right)$ are the values of $g$ at $\theta=0, \pi / 20 ; \pi / 10, \ldots . . . \pi / 2$.

The displacements, strains, and stresses of the fuel pin at any time can be calculated by the following step-by-step iteration procedure:

1. Calculate the elastic displacement, strain, and stress at time zero using equations (7), (2) and (3a).

2. Take a time step, assume a stress change, $\Delta \sigma^{i}\left(\Delta \sigma^{i}=0\right.$ for the first iteration), and calculate the creep strain change according to given material law.

3. Calculate the mid-span displacement change and the total strain change according to equations (8) and (6).

4. Calculate the stress change $\Delta \sigma^{i+1}$ according to equation (3b).

5. Check to see if

$$
\text { TEST }=\left|\frac{\Delta \sigma^{1+1}-\Delta \sigma^{i}}{\Delta \sigma^{i+1}}\right| \leq: 0.005
$$

6. If TEST is bigger than 0.005 , use $\Delta \sigma^{i+1}$ and repeat items 2 through 5 of the procedure.

7. If TEST is less than or equal to 0.005 , add changes of stress, strain and displacement to total stress, strain and displacement respectively, and take another time step. 
In summary, the method calls for the exact satisfaction of the compatibility and stress-strain relations, and the approximate satisfaction of the equilibrium equation through the virtual work principle. Iteration is required because of nonlinearity in the stress-strain relation.

If the mid-span displacement (instead of force) is specified, there is no change in displacement or total strain during any time step. The only equations required for calculation of displacement, strain and stress are (1), (2) and (3a) respectively. The iteration procedure is the same as for the mid-span force case with the exception of eliminating item 3 in the procedure.

PIN OVALLING

Figure 2 shows the ovalling of the fuel pin cross-section under diametrical compression. Ovalling occurs in the pin-wire contact (pinching) planes of fuel bundles. The size of the contact area depends on the pin and wire diameters, relative stiffnesses, wire angle, etc. For a conservative estimate of the ovalling stress, the compression is assumed to be two-dimensional, diametrical, and concentrated. Again the compression can be either force or displacement function of time. The method calls for dividing the total time into steps. The mid-span force or displacement is assumed constant within each time step, and is incremented from step to step. In the following, equations for calculating stress history are presented for the case of force. The same equations and iterative solution procedure are applicable for the case of displacement with minor modification.

Let the deformed shape of the fuel pin cross-section be an ellipse, and the decrease of the diameter in the compression direction equal to the increase of the diameter in the orthogonal direction. Then the major and minor axes of the ellipse are: 

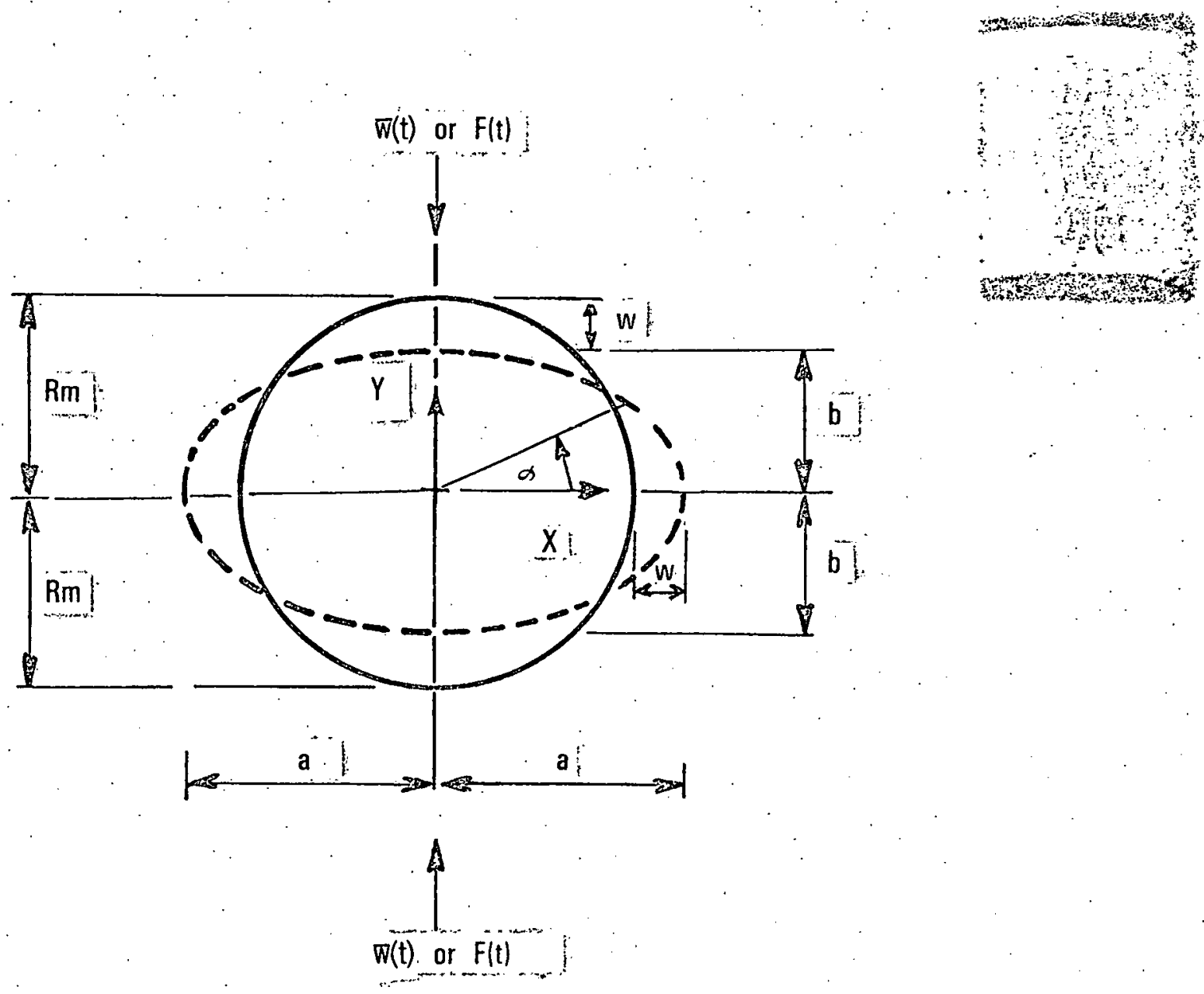

HËDL 7905.060

FIGURE 2. OVALLING OF CLADDING CROSS-SECTION

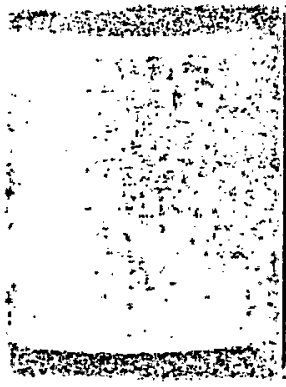




$$
\begin{aligned}
& a=R_{m}+w \\
& b=R_{m}-w
\end{aligned}
$$

The parametric equations for the ellipse are:

$$
\begin{aligned}
& x=a \cos \alpha \\
& y=b \sin \alpha
\end{aligned}
$$

Substituting equation (10) into the general equation for curvature

$$
\kappa=\left|\frac{\frac{d^{2} y}{d x^{2}}}{\left[1+\left(\frac{d y^{2}}{d x}\right)^{3 / 2}\right.}\right| \text {, }
$$

the following is obtained,

$$
\kappa=\frac{a b}{\left(a^{2} \sin ^{2} \alpha+b^{2} \cos ^{2} \alpha\right)^{3 / 2}}
$$

The change in curvature at any point (from circle to ellipse) is

$$
\Delta k=\frac{a b}{\left(a^{2} \sin ^{2} \alpha+b^{2} \cos ^{2} \alpha\right)^{3 / 2}}-\frac{1}{R_{m}}
$$

The differential arc length on the ellipse is

$$
d s=\sqrt{a^{2} \sin ^{2} \alpha+b^{2} \cos ^{2} \alpha} d \alpha
$$

Assuming $w \ll R_{m}$ and retaining only the first two terms of the Binomial series, equations (12) and (13) reduce to: 


$$
\begin{aligned}
& \Delta k=\frac{3 w}{R_{m}^{2}} \cos 2 \alpha \\
& d s=R\left(1-\frac{W}{R_{m}} \cos 2 \alpha\right) d \alpha
\end{aligned}
$$

The strain and strain change of any fiber in the hoop direction are

$$
\begin{aligned}
\varepsilon & =r \Delta k \\
& =\frac{3 w r}{R_{m}^{2}} \cos 2 \alpha \\
\Delta \varepsilon & =\frac{3 w r}{R_{m}^{2}} \cos 2 \alpha
\end{aligned}
$$

The stress and stress change of any fiber in the hoop direction are

$$
\begin{aligned}
& \sigma=E\left(\varepsilon-\varepsilon^{c}\right) \\
& \Delta \sigma=E\left(\Delta \varepsilon-\Delta \varepsilon^{c}\right)
\end{aligned}
$$

Membrane strain, due to thermal expansion, irradiation swelling and internal pressure are neglected in the anlalysis. Lel

$$
\varepsilon^{c}=\varepsilon_{0}^{c} \cos 2 \alpha
$$

Applying the virtual work principle, the following expression for radial displacement at any time is obtained: 


$$
w=\frac{8 R_{m}^{3} F}{3 \pi E t^{3}}+\frac{4 R_{m}^{2}}{t^{3}} \int_{\frac{-t}{2}}^{\frac{t}{2}} r \varepsilon_{0}^{c} d r
$$

For any time step, the change in radial displacement is

$$
\Delta w_{0}=\frac{4 R_{m}^{2}}{t^{3}} \int_{\frac{-t}{2}}^{\frac{t}{2}} r \Delta \varepsilon_{0}^{c} d r
$$

Numerical integration of the right-hand-side of equation (18) can be performed using Newton-Cotes quadrature formula. The displacement, strain, and stress of the fuel pin at any time can be calculated by the same step-by-step iteration procedure as for the pin bending analysis. 
RESULTS.

The methods developed in the preceding section have been implemented in two computer codes, namely, BEND for pin-bending stress calculation, and OVAL for pin ovalling stress calculation. Before the codes were used for stress calculation of fuel pins in the FTR core, their results were checked against MARC-CDC ${ }^{(4)}$ results for constant compression cases. Figure 3 shows the bending stress results for an edge pin with a $3.4 \mathrm{~cm}(1.333 \mathrm{in.})$ unsupported span corresponding to a wire axial pitch of $20.3 \mathrm{~cm}(8 \mathrm{in.})$. The mid-span displacement is $0.127 \mathrm{~mm}(0.005 \mathrm{in}$.$) constant with time. The dimensions of$ the pin are $5.84 \mathrm{~mm}(0.230 \mathrm{in.})$ in outside diameter, and $0.381 \mathrm{~mm}(0.015 \mathrm{in.})$ in thickness. The temperature and fast neutron flux are $811^{\circ} \mathrm{K}\left(1000^{\circ} \mathrm{F}\right)$ and $5 \times 10^{15} \mathrm{n} / \mathrm{cm}^{2}$-sec respectively. The pin material is $316 \mathrm{SS} 20 \% \mathrm{CW}$. Revision 5 irradiation creep of the Nuclear Systems Materials Handbook was used in the analysis. In Figure 3 the solid curve and the dashed curve correspond to MARC-CDC and BEND results respectively. The results are in close agreement, and the particular creep law used provides fast relaxation of stress. Figure 4 shows the ovalling stress results for a pin. The diametrical compression is $0.076 \mathrm{~mm}(0.003 \mathrm{in.})$ constant with time. The dimensions, temperature, fast neutron flux, and material properties are the same as those for the pin bending check case. The results are in reasonable agreement with each other. In the pin bending analysis, the deformed shape assumed is a cubic function which is the exact solution. In the pin ovalling analysis, the deformed shape assumed is an ellipse which is not the true shape. That is why, the agreement between results is better for the pin bending case than for the pin ovalling case. In any event, uncertainties involved in related analytical predictions (like environmental data, material law, bundle-duct interference, etc.) do not warrant exact calculation of stresses. It is to be noted that the relative computer costs for running MARC-CDC and (BEND or OVAL) for the test cases were 50 to 1 .

Having established agreement with the MARC-CDC program, the BEND and OVAL codes were used to predict the bending and ovalling stresses of fuel pin 


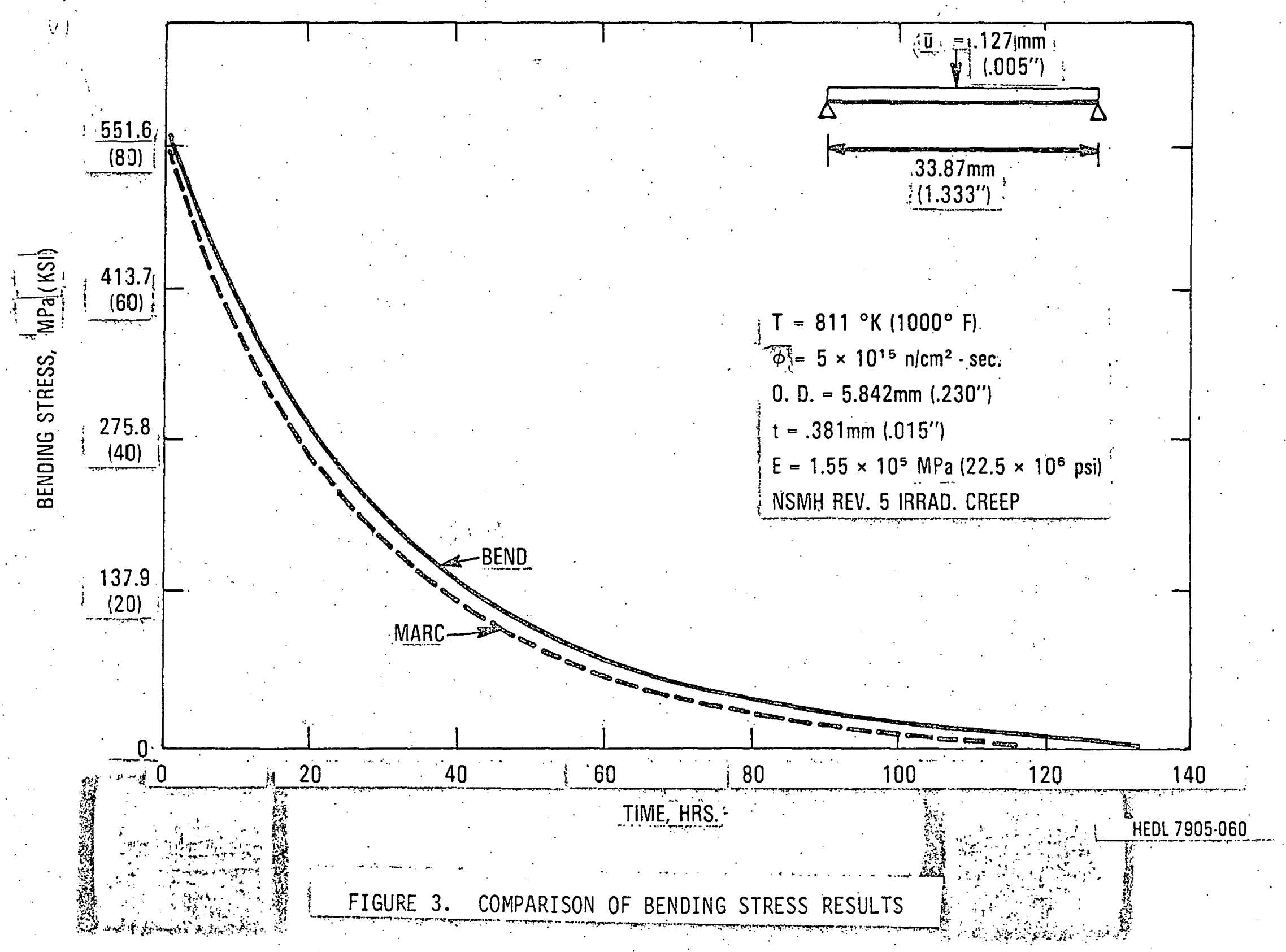




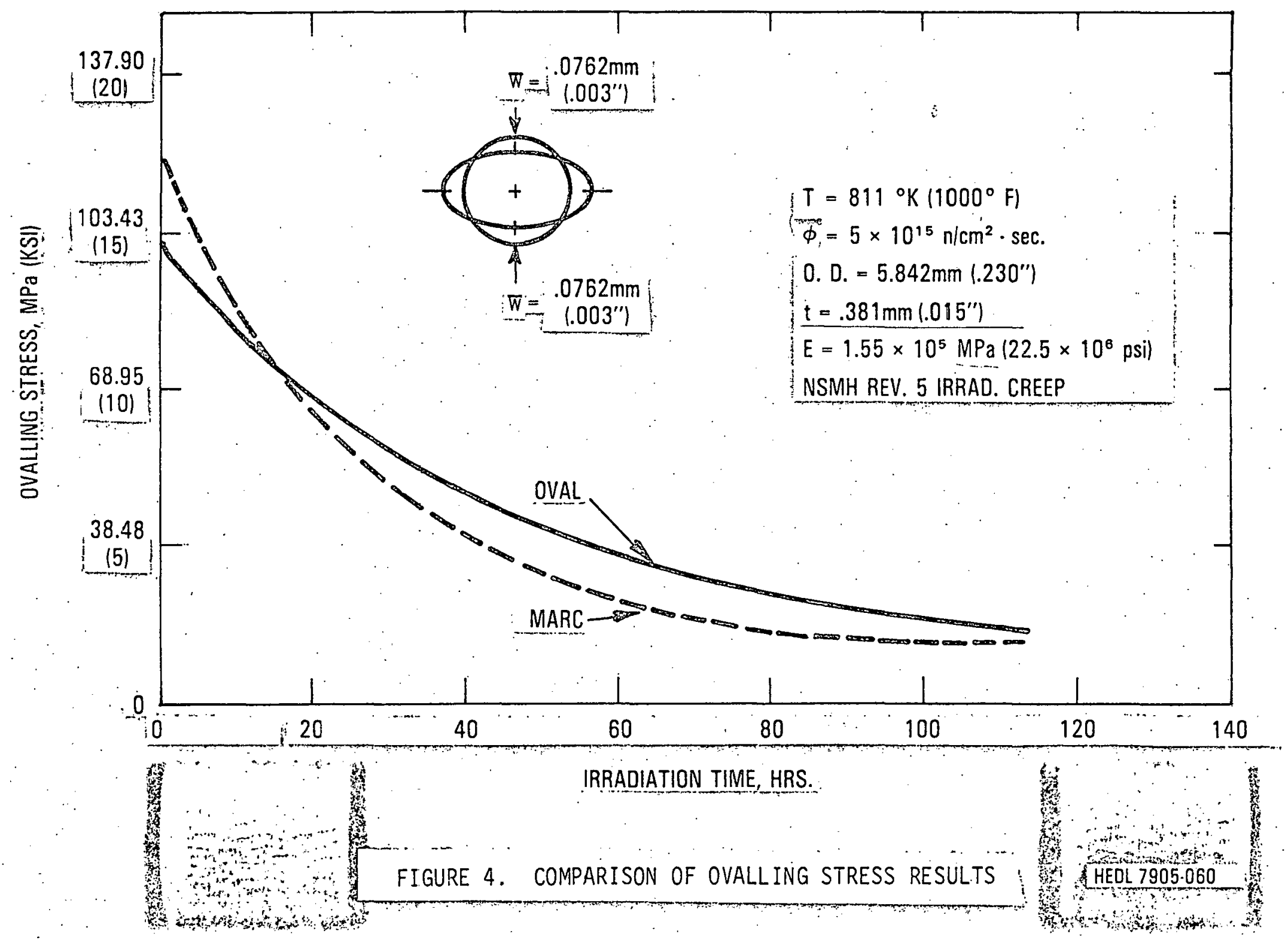


cladding in the FTR core. The parameters varied were the compression rate, wire-wrap axial pitch, and the fast neutron flux. Shown in Table 1 are the pin bending and ovalling rates corresponding to three bundle-duct interference rates. The medium interference rate of $0.51 \times 10^{-3} \mathrm{~mm} / \mathrm{hr} .\left(20 \times 10^{-3} \mathrm{mi} \mathrm{s} / \mathrm{hr}\right.$. $)$ is that of the reference driver fuel assembly in row 1 postion of the FTR core. The low interference rate of $0.25 \times 10^{-3} \mathrm{~mm} / \mathrm{hr}$. $\left(10 \times 10^{-3} \mathrm{mils} / \mathrm{hr}.\right)$ is that of the reference driver fuel assembly in an outer row position where the fast neutron flux is less and therefore the differential swelling between the bundle and the duct is less. The high interference rate of $0.76 \times 10^{-3} \mathrm{~mm} / \mathrm{hr}$. $\left(30 \times 10^{-3} \mathrm{mils} / \mathrm{hr}.\right)$ is that of a reference bundle in an advanced alloy duct which has less swelling characteristics. All interferences rates are estimated mean values over 3 cycles. Pins of reference dimension, and NSMH Revision 5 irradiation creep 1 aw were assumed. It was further assumed that the bundle-duct contact occurred at the end of $11 / 2$ reactor cycles (3600 hrs.).

Figure 5 shows the variation of pin bending stresses with time for three different wire-wrap axial pitches. The temperature, flux, and bundle-duct interference rate correspond to those of a reference assembly in row 1 postion. The bending stresses increase nonlinearly with time, and reach steady state values in approximately $160 \mathrm{hrs}$. Physically at the beginning of bundleduct interference, the bending stress created is low, and therefore the creep relaxation (which is dependent on stress) is also low. Stress continues to increase because of increasing bundle-duct interference to a point such that the creep relaxation balances increasing bundle-duct interference. The steady-state bending stress values for $15.2 \mathrm{~cm}(6 \mathrm{in.})$ and $20.3 \mathrm{~cm}(8 \mathrm{in.})$ axial pitch pins are almost the same at $5.5 \mathrm{MPa}(0.8 \mathrm{ksi})$. The steady state value for $30.5 \mathrm{~cm}$ (12 in.) pitch pin is $4.1 \mathrm{MPa}(0.6 \mathrm{ksi})$. Even though the bending compression rates go down as the wire pitch is reduced, Table 1, the shortening of the unsupported span causes the stress to go up. For the 15.2 $\mathrm{cm}$ ( 6 in.) and the $20.3 \mathrm{~cm}$ ( 8 in.) wire pitch cases, the two effects offset each other to produce essentially the same stress curve in Figure 5 . For comparison, the stress rupture of $316 \mathrm{SS} 20 \% \mathrm{CW}$ at $811 \mathrm{k}(1000 \mathrm{~F}$ ) in 3 cycles (7200 hrs.) is approximately $248 \mathrm{MPa}(36 \mathrm{ksi})$. 
TABLE 1

COMPRESSION RATES $10^{-3} \mathrm{~mm} / \mathrm{hr}\left(10^{-3} \mathrm{mi} / \mathrm{s} / \mathrm{hr}\right)$

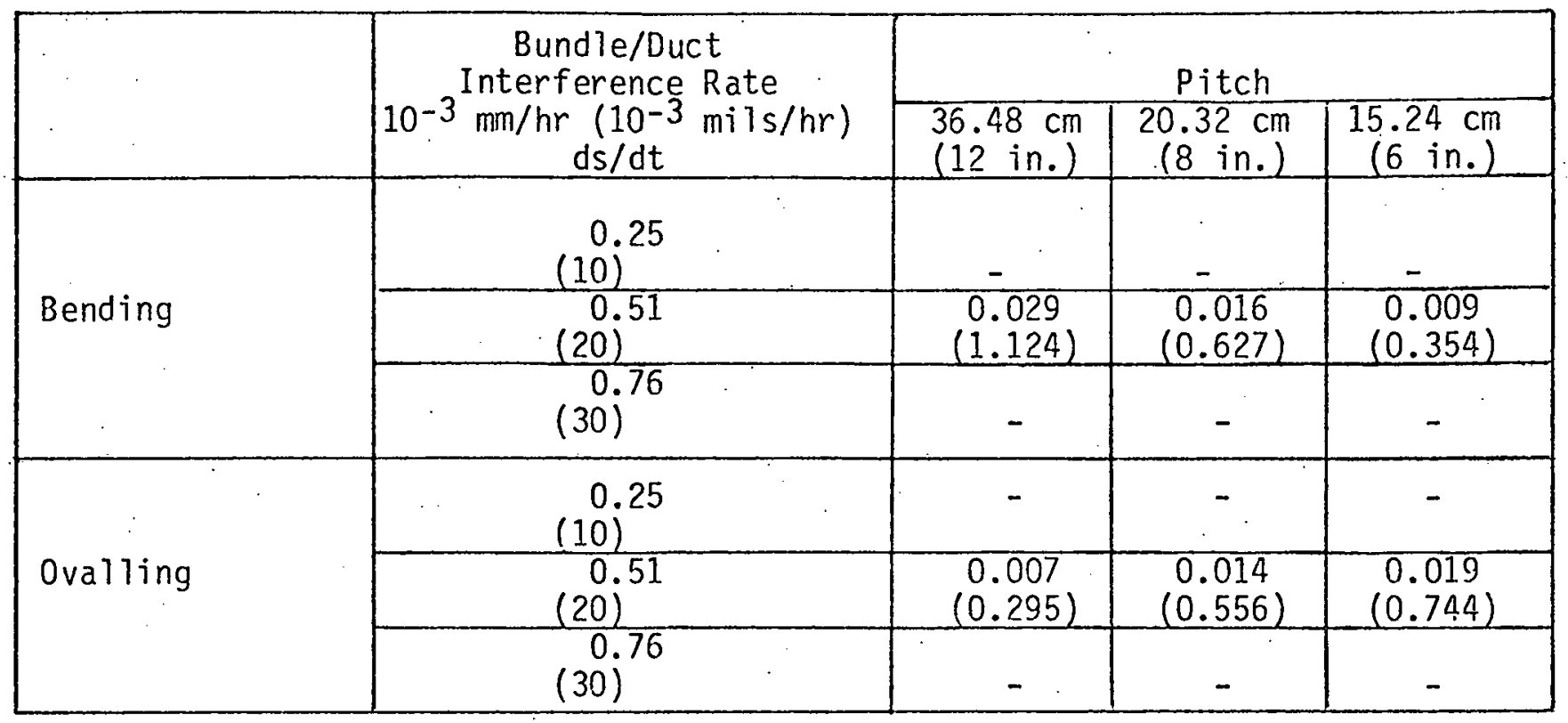




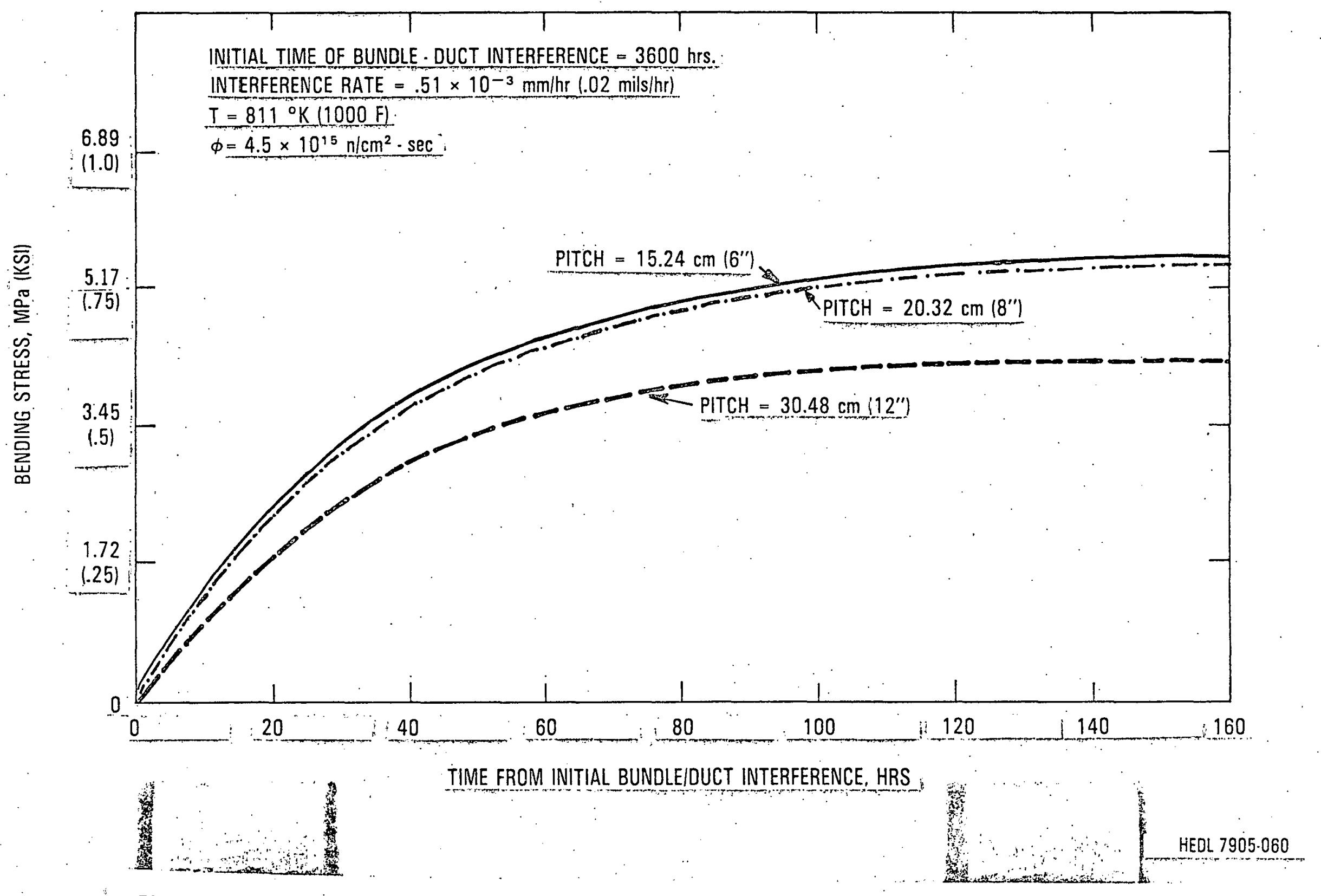

FIGURE 5. VARIATION OF BENDING STRESS WITH IRRADIATION TIME AND WIRE AXIAL PITCH 
Figure 6 shows the variation of pin bending stress with fast neutron flux for three different bundle-duct interference rates. As expected, the stress decreases with fast neutron flux and bundle-duct interference rate. Even with the highest bundle-duct interference rate and the lowest fast neutron flux for creep relaxation, the stress is still well below the stress rupture value.

Figure 7 shows the variation of pin ovalling stresses with time for three different wire axial pitches. The temperature, flux and bundle-duct interference rate correspond to those of a reference assembly in row 1 postion. The ovalling stresses increase nonlinearly with time and reach steady state values in approximately $160 \mathrm{hrs}$. The steady state values for $15.2 \mathrm{~cm}$ (6 in.), $20.3 \mathrm{~cm}(8 \mathrm{in.})$ and $30.5 \mathrm{~cm}$ (12 in.) axial pitch cases are $8.6 \mathrm{MPa}$ $(1.25 \mathrm{ksi}), 6.4 \mathrm{MPa}(0.93 \mathrm{ksi})$, and $3.4 \mathrm{MPa}(0.50 \mathrm{ksi})$ respectively. The increase of stress with decreasing wire pitch is due to increasing compression rate with decreasing wire pitch, Table 1.

Figure 8 shows the variation of pin ovalling stress with fast neutron flux for three different bundle-duct interference rates. As expected, the stress decreases with fast neutron flux and bundle-duct interference rate. Even with the highest bundle-duct interference rate and the lowest fast neutron flux for creep relaxation, the stress is still below the stress rupture value. 


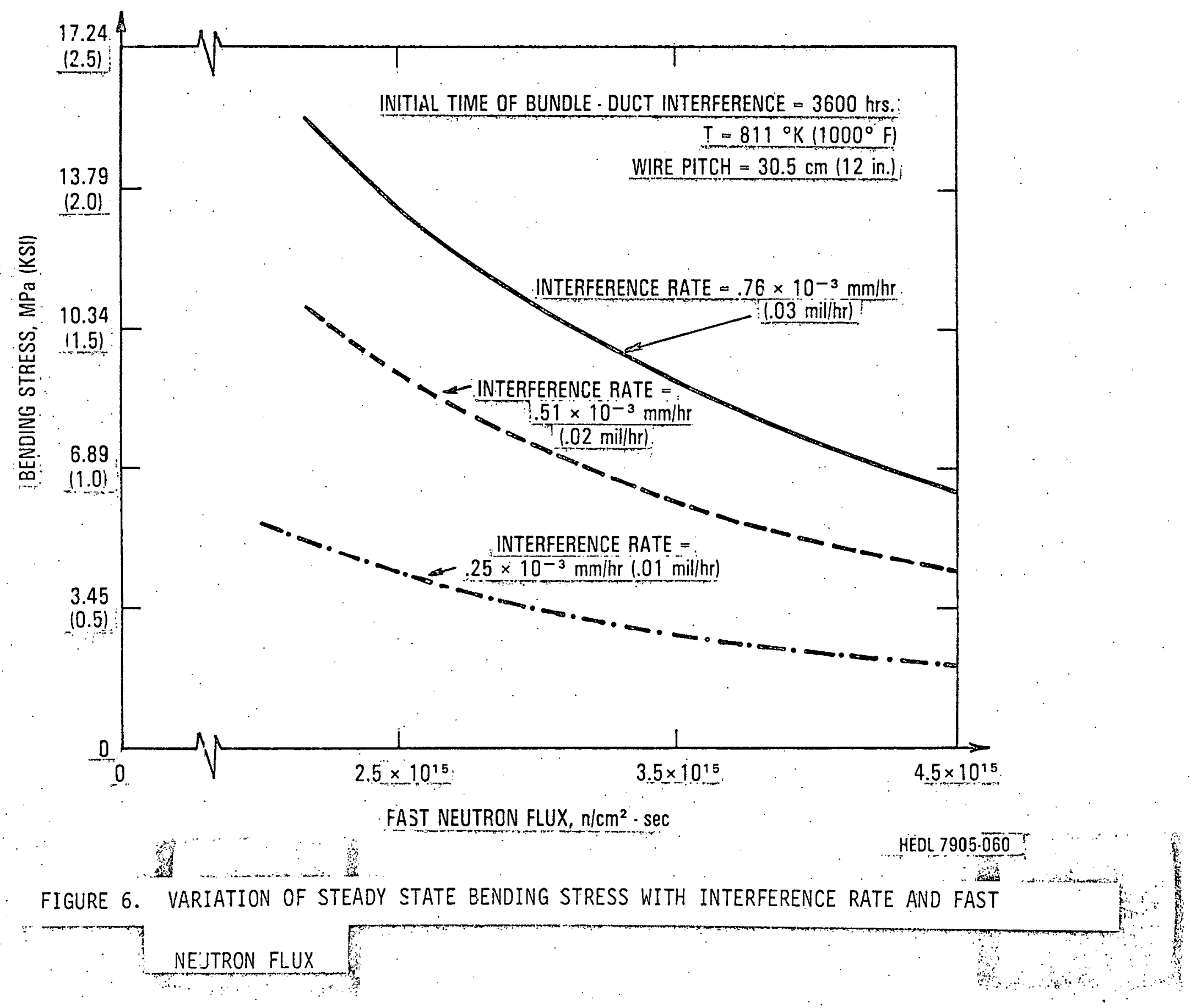




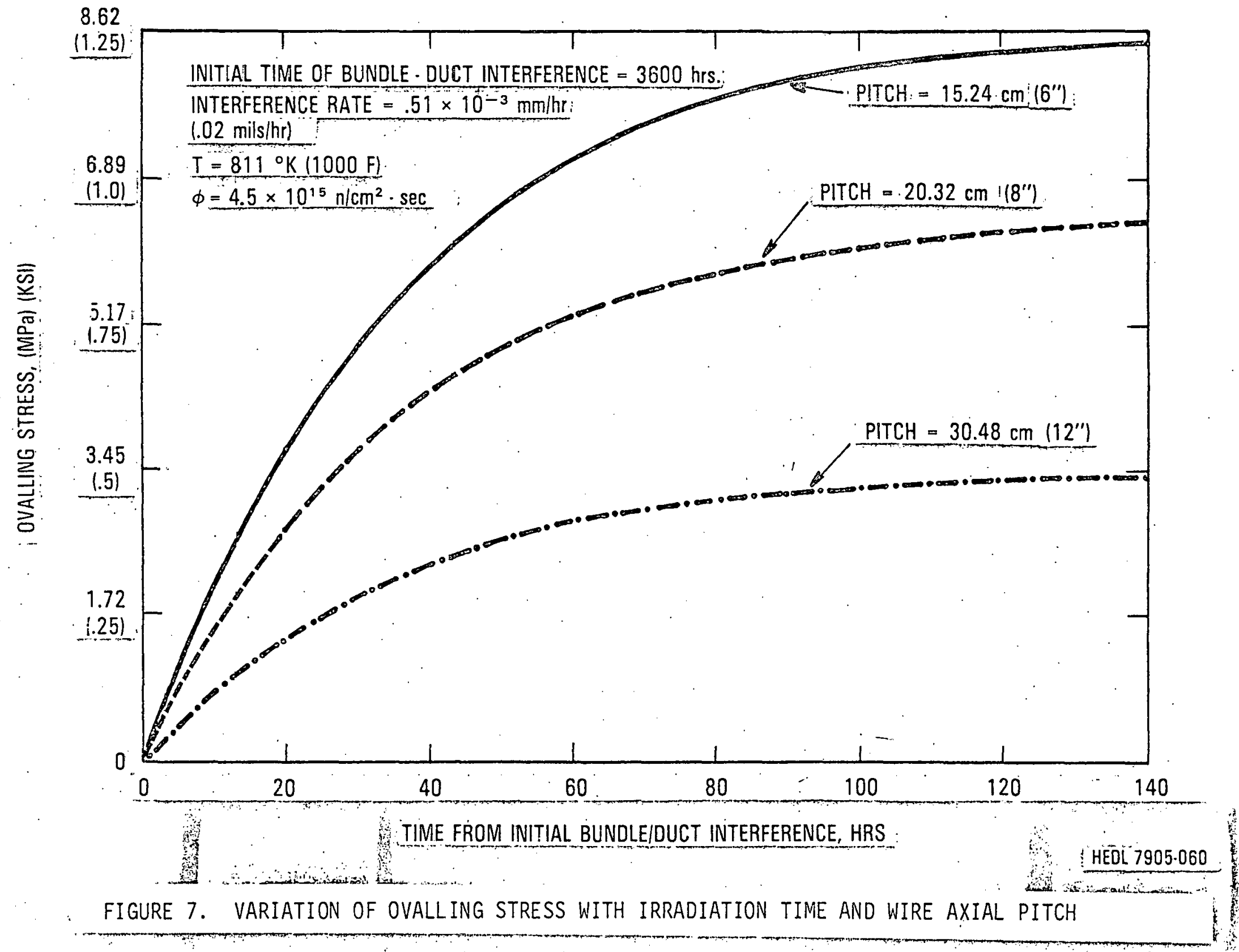




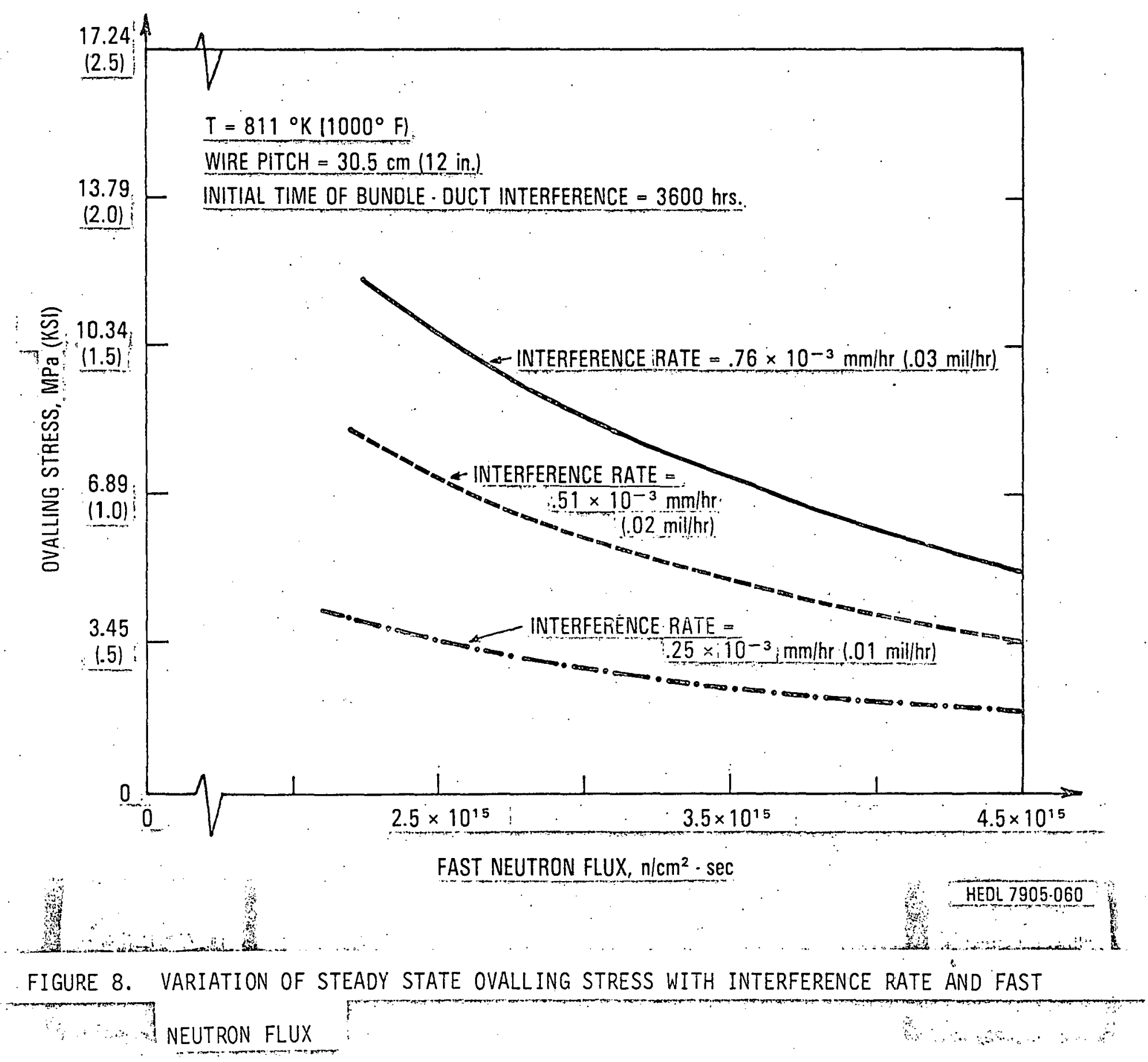




\section{CONCLUSIONS}

On the basis of the results obtained, the following conclusions are drawn:

1. Methods have been developed which can be used to calculate the bending and ovalling stresses in the fuel pins taking into account the effects of nonlinear creep.

2. The driver fuel pin cladding of 316 SS $20 \% \mathrm{CW}$ and reference design has high creep rate in the FTR core region to keep the bending and ovalling stresses to low levels. 
1. R. G. Hill, R. J. Jackson, "Bundle-Duct Clearance of HEDL Mixed Oxide Subassemblies," HEDL-TME 76-29, June 1977, Westinghouse Hanford Company Richland, Washington.

2. D. P. Chan, R. J. Jackson, "Fuel Pin Bundle and Hexagonal Duct Mechanical Interaction," 78-PVP-48, Joint ASME/CSME Pressure Vessels and Piping Conference, Montreal, Canada, June 25-30, 1978.

3. D. P. Chan, R. J. Jackson, "Thermal Bowing of Wire-Wrapped Fuel Pins in Fast Reactors," ANS Winter Annual Meeting November 11-16, 1979, San Francisco.

4. "MARC-CDC, General Purpose Finite Element Analysis Program," Rev. J, 1977, Control Data Corporation, Minneapolis, M.N. 